\title{
Toward individualized management of the ascending aorta in bicuspid aortic valve surgery: The role of valve phenotype in 1362 patients
}

\author{
Hans-Hinrich Sievers, MD, Ulrich Stierle, MD, Salah A. Mohamed, PhD, MD, Thorsten Hanke, MD, \\ Doreen Richardt, MD, Claudia Schmidtke, MD, and Efstratios I. Charitos, MD
}

\begin{abstract}
Objective: Decision making regarding the management of the ascending aorta (AA) in patients with a bicuspid aortic valve (BAV) undergoing valve surgery has hardly been individualized and remains controversial. We analyzed our individualized, multifactorial approach, focusing on the BAV phenotype.
\end{abstract}

\begin{abstract}
Methods: In 1362 patients (1044 men) undergoing aortic valve surgery, the BAV phenotypes were intraoperatively classified and retrospectively analyzed. The mean follow-up was $5.4 \pm 3.6$ years (range, $0-14 ; 7334$ patient-years), and the data were $96.5 \%$ complete. The individualized AA management decision process mainly included the AA diameter, age, body surface area, macroscopic AA configuration, and the perceived tissue strength of the aortic wall resulting in 3 AA treatment groups: no intervention, aortoplasty (AoP), and AA replacement (AAR).
\end{abstract}

Results: In 906 patients (66.5\%), no intervention was performed and $172(12.6 \%)$ and $284(20.9 \%)$ underwent AoP and AAR, respectively. The hospital mortality was $1.1 \%$ for no intervention, $0.6 \%$ for AoP, and $0.4 \%$ for AAR $(P=.4)$. The 10 -year survival was similar for all 3 groups and comparable to that of the general population. Five reoperations on the AA occurred, 4 in the no intervention and 1 in the AoP group. BAV type 2/unicuspid patients were younger and more had undergone AAR in absolute numbers and after allowing for the AA diameter. Also, in patients with BAV type $1 \mathrm{LR}$ and regurgitation, AAR was performed more often.

Conclusions: The individualized, multifactorial management of AA in patients with BAV during aortic valve surgery leads to excellent results. The threshold AA diameter for intervention (AoP or AAR) varied from 34 to $51 \mathrm{~mm}$ (mean, 43.9). BAV type 2/unicuspid and BAV type $1 \mathrm{LR}$ with regurgitation emerged as determinants for more liberal AAR in our practice. Longer term follow-up is necessary to confirm our conclusions. (J Thorac Cardiovasc Surg 2014;148:2072-80)

See related commentary on pages 2080-1.

Supplemental material is available online.

Increasing research on bicuspid aortic valve (BAV) disease during the past decade has underscored its increasing importance as the most frequent congenital malformation. It has a $1 \%$ to $2 \%$ incidence in the general population, imposing a considerable health burden. ${ }^{1}$ Not only the

From the Department of Cardiac and Thoracic Vascular Surgery, University of Lübeck, Lübeck, Germany.

Disclosures: Authors have nothing to disclose with regard to commercial support. Received for publication Jan 7, 2014; revisions received March 21, 2014; accepted for publication April 4, 2014; available ahead of print May 17, 2014.

Address for reprints: Hans-Hinrich Sievers, MD, Department of Cardiac and Thoracic Vascular Surgery, University of Lübeck, Ratzeburger Allee 160, Lübeck 23538, Germany (E-mail: Hans-Hinrich.Sievers@uksh.de).

$0022-5223 / \$ 36.00$

Copyright (c) 2014 by The American Association for Thoracic Surgery

http://dx.doi.org/10.1016/j.jtcvs.2014.04.007 valvulopathy, but especially the BAV-associated aortopathy, has attracted clinical and scientific attention. A 6- to 9-fold increased risk of aortic complications such as rupture and dissection in patients with BAV compared with the general population has been reported. ${ }^{2-4}$ Therefore, it is of significant therapeutic relevance to investigate how to treat the dilated ascending aorta (AA) at valve surgery. Previously, the decision has mainly been determined by the AA diameter. It has been well accepted that AA replacement (AAR) is indicated for larger diameters. However, considerable debate has ensued on how to treat patients with a smaller AA diameter. ${ }^{\mathrm{E}, 5,6}$ Recently, a large survey uncovered large gaps in knowledge and attitudes among surgeons regarding how to treat BAV aortopathy. ${ }^{5}$ In addition to the diameter of the AA, additional factors such as the quality or pathologic features of the aortic wall could be associated with the risk of AA complications. Several reports have showed that the histologic features of the AA wall in BAV will not be normal and might be related to genetic abnormalities. ${ }^{3,7}$ However, some evidence has shown that hemodynamics play a role in the dilatation process. ${ }^{8,9}$ It is probable that both genetics and hemodynamics are important interacting 


$$
\begin{aligned}
& \text { Abbreviations and Acronyms } \\
& \begin{aligned}
\text { AA } & =\text { ascending aorta } \\
\text { AoP } & =\text { aortoplasty } \\
\text { BAV } & =\text { bicuspid aortic valve } \\
\text { BSA } & =\text { body surface area } \\
\text { LR }= & \text { raphe between left coronary and right } \\
& \text { coronary sinuses }
\end{aligned}
\end{aligned}
$$

factors. $^{2}$ In this context, it has been suspected that the various phenotypes of the BAV could be associated with AA dilatation. To answer the question of whether the phenotypes of BAV could serve as determinants for decision making, we analyzed our management protocol of the AA during valve surgery in 1362 patients with BAV with a special focus on the BAV phenotypes.

\section{METHODS \\ Patients}

A total of 1663 patients with BAV and without associated genetic syndromes (eg, Marfan, Loeys-Dietz, transforming growth factor- $\beta$ receptor 1 or 2 mutation, Turner) underwent cardiac surgery from February 1999 to April 2013. A total of 1476 consecutive patients with BAVs $(88.8 \%)$ were classified during surgery. The missing classifications occurred because during our initial experience, the presence of BAV was recorded but we had no awareness to differentiate the phenotype. We excluded 15 patients with acute type A dissection, 30 patients with endocarditis, and 9 patients who did not undergo valve surgery. Also, 60 patients were excluded because of previous cardiac surgery. The final sample size consisted of 1362 patients with intraoperatively classified BAVs. The patient characteristics, valve procedures, pre- and intraoperative data, and BAV phenotypes are listed in Table 1. The follow-up data for these 1362 patients were $96.5 \%$ complete. The follow-up period ranged from 0 to 14 years (mean, $5.4 \pm 3.6$ ), with a cumulative follow-up duration of 7334 patient-years (no intervention, 4880 patient-years, 96.6\% complete; aortoplasty [AoP], 1012 patient-years, 98.3\% complete; AAR, 1441 patient-years, $95.4 \%$ complete). The follow-up protocol consisted of outpatient visits and written questionnaires to the family doctor. The local ethics committee of the University of Lübeck approved the present study.

\section{BAV Classification}

BAV is a collective term for aortic valves with the characteristic oval, fish mouth-like orifice but with different phenotypes. Classification of the BAV phenotype is necessary to evaluate the phenotype-related effects and is sine qua non for accurate scientific communication. Our classification of the $\mathrm{BAV}$ is a raphe- or fusion-related description. ${ }^{10}$ In brief, the classification system was based on macroscopic observation during valve surgery. The resulting nomenclature is intuitive and self-explanatory, covering the whole spectrum of phenotypes of the BAV complex. ${ }^{10}$ The so-called unicuspid valve has been included in the BAV classification system as BAV type $2,{ }^{10}$ because it also presents with the typical fish mouth-like bifoliate orifice and has raphes and developed and underdeveloped commissures, in principle similar to the morphologic characteristics of the classic BAV type 1 . Other investigators have also supported the concept that the unicuspid valve shares many features of the classic BAV. ${ }^{11}$ To underline this connection, the term "unicuspid" has now been added to BAV type 2, reading BAV type 2/unicuspid. Only the most frequently observed types of BAV are shown in Figure 1; however, Tables 1 and E1 include all recorded BAV types.

\section{Hemodynamics, Indication for Surgery and Diameter Measurement}

Preoperatively, the pressure gradient across the aortic valve was measured using angiocardiography or echocardiography. Aortic insufficiency was assessed using color flow Doppler techniques and graded by the jet height in relation to the left ventricular outflow tract height. ${ }^{10}$ The indications for surgery were according to the American College of Cardiology/American Heart Association guidelines. ${ }^{\mathrm{E}}$ The maximal AA diameter was measured preoperatively on a CT scan, angiocardiogram, or echocardiogram and intraoperatively by direct measurement. The diameters were seldom measured or recorded when they were perceived to be normal $(<40 \mathrm{~mm})$.

\section{Strategy for AA Management}

Our decision-making process for AA management was, in principle, guided, but not strictly limited, by the fixed guideline ${ }^{\mathrm{E} 1}$ threshold AA diameter of $45 \mathrm{~mm}$. Other factors that influenced the decision were the body surface area (BSA) and the age-related upper 2 standard deviation limit of the normal AA diameter, leading to lower individualized and variable thresholds. ${ }^{12}$ Additional parameters such as the perceived strength of the AA wall (fragility and thickness), which was judged during aortotomy for valve surgery, played a role. A progressive increase of the AA diameter $(>0.5 \mathrm{~cm} / \mathrm{y})$ and family history were also integrated into the decision-making process, as appropriate. However, these factors seldom occurred. Intervention on the AA was performed as AAR or AoP. The parameters in favor of AAR were a larger diameter and/or tubular configuration of the dilation, especially if the aortic arch was involved (Fazel cluster III and $\mathrm{IV}^{13}$ ), younger age, the perceived fragility of the wall tissue, rarely, a significant increase in the diameter of $>0.5 \mathrm{~cm}$ in the previous year, and a positive family history. The fragility of the wall tissue was assumed when (1) placement of the cannulation sutures and snaring tourniquets for cannula fixation caused bleeding and/or hematoma around the cannulation site; (2) stay sutures above the commissures showed unusual tearing through the wall; (3) aortotomy revealed thinning of the wall; and/or (4) a pale vasa vasorum free area was present in the AA wall. Parameters favoring AoP included eccentric, borderline dilatation confined to the lateral AA wall (Fazel cluster $\mathrm{II}^{13}$ ), a normal appearing quality of the AA wall, older age, no positive family history, and no significant progression of the AA diameter, documented from previous examinations. Parameters favoring no intervention included a smaller diameter, older age, a high surgical risk, and severe comorbidities (Figure 2). Thus, the decision to intervene was a combination of quantitative and qualitative multifactorial, individualized parameters. Furthermore, the final decision was also influenced by surgeon preference.

\section{Surgical Technique}

Standard cardiopulmonary bypass with cannulation of the aortic arch was used at hypothermia of $28^{\circ} \mathrm{C}$ to $30^{\circ} \mathrm{C}$ nasopharyngeal temperature in all patients. Dacron grafts (DuPont, Wilmington, Del), size 28 to 32, were used for AAR, relative to the patient's size. The distal and proximal suture lines were reinforced with a strip of Teflon felt (DuPont). In the case of hemiarch replacement, cardiopulmonary arrest at $18^{\circ} \mathrm{C}$ was applied for 20 minutes; thereafter, antegrade cerebral perfusion was initiated. AoP was performed as a plication of the wall between 2 Teflon felts (Figure E1). The proximal part of the AoP was performed during clamping of the AA and the distal third after declamping and de-airing.

\section{Statistical Analysis}

Descriptive variables are presented as the mean \pm standard deviation and categorical variables as absolute and relative frequencies. The $P$ values of 2-sided tests are reported. For comparisons of the descriptive characteristics, simple statistical tests $(t$ test, chi-square test, analysis of variance, Wilcoxon-Mann-Whitney test) were used as appropriate. 
TABLE 1. Demographic and pre- and intraoperative clinical data $(n=1362)$

\begin{tabular}{|c|c|c|c|c|c|}
\hline Variable & Total $(n=1362)$ & BAV type $0(n=115)$ & BAV type $1(n=1078)$ & BAV type $2(n=169)$ & $P$ value \\
\hline BAV subtype & & & & & - \\
\hline ap, LR, LR/RN & - & ap $48(41.7)$ & LR 888 (82.4) & LR/RN 153 (90.5) & \\
\hline lat, NL, LR/NL & - & lat $58(50.4)$ & NL $22(2.0)$ & LR/NL 6 (3.6) & \\
\hline $\mathrm{RN}, \mathrm{RN} / \mathrm{NL}$ & - & - & RN 166 (15.4) & RN/NL 6 (3.6) & \\
\hline Age (y) & $56.6 \pm 14.9$ & $54.2 \pm 13.4$ & $58.8 \pm 14.3$ & $44.7 \pm 13.4$ & $*, \dagger, \ddagger$ \\
\hline $\operatorname{BSA}\left(m^{2}\right)$ & $1.98 \pm 0.21$ & $1.97 \pm 0.21$ & $1.98 \pm 0.21$ & $1.97 \pm 0.2$ & NS \\
\hline Male gender & $1044(76.7)$ & $87(75.7)$ & $833(77.3)$ & $124(73.4)$ & NS \\
\hline Hypertension & 907 (66.6) & $69(60)$ & $754(69.9)$ & $84(49.7)$ & \\
\hline \multicolumn{6}{|l|}{ LVEF (\%) } \\
\hline$<30$ & $37(2.7)$ & $0(0)$ & $34(3.2)$ & $3(1.8)$ & \\
\hline $30-50$ & $195(14.3)$ & $13(11.3)$ & $166(15.4)$ & $16(9.5)$ & \\
\hline$>50$ & $1054(77.4)$ & $95(82.6)$ & $811(75.2)$ & $148(87.6)$ & \\
\hline Unknown & $76(5.6)$ & $7(6.1)$ & $67(6.2)$ & $2(1.2)$ & \\
\hline \multicolumn{6}{|l|}{ NYHA } \\
\hline I & $332(24.4)$ & $25(21.7)$ & $260(24.1)$ & $47(27.8)$ & \\
\hline II & $486(35.7)$ & $44(38.3)$ & 367 (34) & $75(44.4)$ & \\
\hline III & $412(30.2)$ & $38(33)$ & $329(30.5)$ & $45(26.6)$ & \\
\hline IV & $43(3.2)$ & $0(0)$ & $41(3.8)$ & $1(0.6)$ & \\
\hline Unknown & $89(6.5)$ & $7(6.1)$ & $81(7.5)$ & $1(0.6)$ & \\
\hline Diabetes & $162(11.9)$ & $9(7.8)$ & $147(13.6)$ & $6(3.6)$ & \\
\hline COPD & $104(7.6)$ & $4(3.5)$ & $92(8.5)$ & $8(4.7)$ & \\
\hline \multicolumn{6}{|l|}{ AA procedure } \\
\hline No intervention & $906(66.5)$ & $78(67.8)$ & $741(68.7)$ & $87(51.5)$ & $\ddagger, \S$ \\
\hline \multicolumn{6}{|l|}{ Intervention } \\
\hline AAR & $284(20.9)$ & $25(21.7)$ & $196(18.2)$ & $63(37.3)$ & $\ddagger, \S$ \\
\hline Circulatory arrest (hemiarch) & $158(11.6)$ & $10(8.7)$ & $107(9.9)$ & $41(24.3)$ & $\ddagger, \S$ \\
\hline $\mathrm{AoP}$ & $172(12.6)$ & $12(10.4)$ & $141(13.1)$ & $19(11.2)$ & \\
\hline AA diameter $(\mathrm{mm})$ & $43.0 \pm 9.3(\mathrm{n}=974)$ & $41.9 \pm 8.5(\mathrm{n}=78)$ & $42.9 \pm 9.5(\mathrm{n}=741)$ & $43.9 \pm 8.8(\mathrm{n}=155)$ & NS \\
\hline \multicolumn{6}{|l|}{ Aortic valve lesion } \\
\hline Stenosis & $614(45.1)$ & $64(55.7)$ & $482(44.7)$ & $68(40.2)$ & \\
\hline Insufficiency & $268(19.7)$ & $24(20.9)$ & $240(22.3)$ & $4(2.4)$ & \\
\hline Combined & $480(35.2)$ & $27(23.5)$ & $356(33)$ & $97(57.4)$ & \\
\hline \multicolumn{6}{|l|}{ Aortic valve procedure } \\
\hline Repair & $142(10.4)$ & $16(13.9)$ & $122(11.3)$ & $4(2.4)$ & \\
\hline Ross & $337(24.7)$ & $19(16.5)$ & $217(20.1)$ & $101(59.8)$ & \\
\hline Biologic valve & $620(45.5)$ & $40(34.8)$ & $540(50.1)$ & $40(23.7)$ & \\
\hline Mechanical valve & $263(19.3)$ & $40(34.8)$ & $199(18.5)$ & $24(14.2)$ & \\
\hline Bypass time (min) & $152.1 \pm 63.2$ & $135.5 \pm 59$ & $146.4 \pm 61.1$ & $194.9 \pm 60.5$ & \\
\hline Crossclamp time (min) & $124.1 \pm 56.1$ & $109.6 \pm 51.1$ & $118.7 \pm 53.8$ & $163.5 \pm 55.6$ & \\
\hline Mitral valve surgery & $49(3.6)$ & $4(3.5)$ & $40(3.7)$ & $5(3)$ & \\
\hline Tricuspid valve surgery & $8(0.6)$ & $1(0.9)$ & $6(0.6)$ & $1(0.6)$ & \\
\hline CABG & $244(17.9)$ & $14(12.2)$ & $222(20.6)$ & $8(4.7)$ & \\
\hline Root reconstruction & $80(5.9)$ & $9(7.8)$ & $58(5.4)$ & $13(7.7)$ & \\
\hline Bentall & $65(4.8)$ & $6(5.2)$ & $51(4.7)$ & $8(4.7)$ & \\
\hline David & $37(2.7)$ & $5(4.3)$ & $31(2.9)$ & $1(0.6)$ & \\
\hline Yacoub & $11(0.8)$ & $1(0.9)$ & $10(0.9)$ & $0(0)$ & \\
\hline
\end{tabular}

Data presented as $\mathrm{n}(\%)$ or mean \pm standard deviation. $B A V$, Bicuspid aortic valve; $a p$, anteroposterior; $L R$, raphe between left coronary and right coronary sinuses; $R N$, raphe between right coronary and noncoronary sinuses; lat, lateral; $N L$, raphe between noncoronary and left coronary sinuses; $B S A$, body surface area; $L V E F$, left ventricular ejection fraction; NYHA, New York Heart Association (functional classification); COPD, chronic obstructive pulmonary disease; AA, ascending aorta; $A A R$, AA replacement; $A o P$, aortoplasty; $C A B G$, coronary artery bypass grafting. ${ }^{*}$ Type 0 versus type $1, P<.01$. $\dagger$ Type 0 versus type $2, P<.001$. $\ddagger$ Type 1 versus type $2, P<.001$. $\S$ Type 0 versus type $2, P<.01$.

The time-to-event outcomes were analyzed using survival methods (Kaplan-Meier, Cox proportional odds). The late postoperative survival of the population and subgroups was compared to the survival expected from the age- and gender-adjusted general population (available at: www.destatis.de). ${ }^{14}$
Binary and multinomial logistic regression analysis was used to investigate the factors that influenced the decision to perform an intervention on the AA (AAR or AoP). The following factors were investigated: AA diameter, available for 975 patients ( $96.3 \%$ of the interventions), age, BAV phenotype, and BSA. The AA size was forced into all models, and 


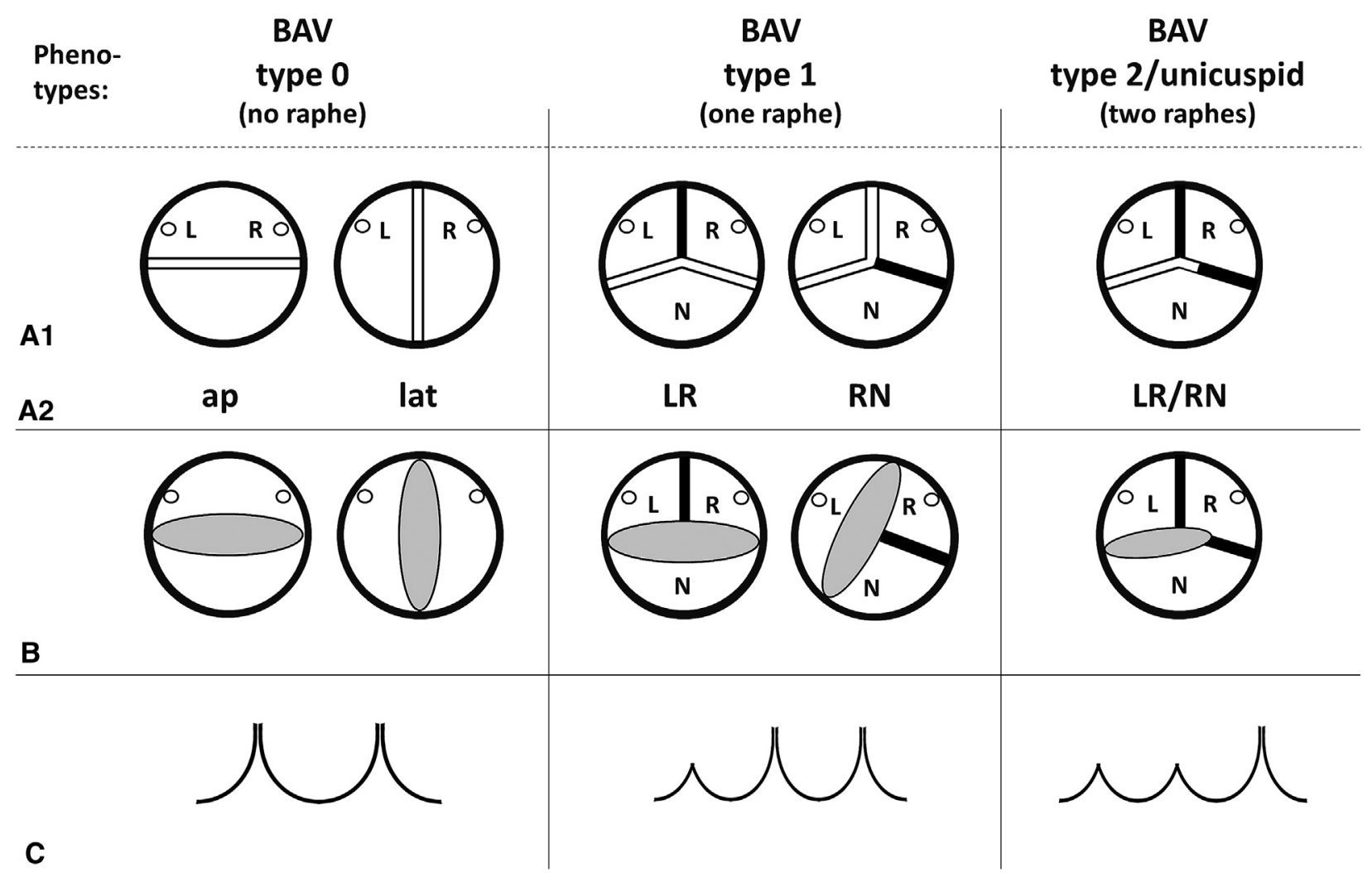

FIGURE 1. Schematic presentation of the classification system of the most frequent bicuspid aortic valve (BAV) phenotypes according to (A1) the number of raphes or fusions and (A2) the spatial position of the commissures for type 0 and the raphes for types 1 and 2/unicuspid as viewed by the surgeon on the right side of the patient. B, The spatial orientation of the characteristic of a BAV, with the fish mouth-like bifoliate valve opening shown. C, The developmental state of the commissures. Thick line in the circle, Raphe; small circles, coronary ostia; shaded, valve opening area; $L$, left; $R$, right; ap, anteroposterior; lat, lateral; $N$, noncoronary; $L R$, raphe between left coronary and right coronary sinuses; $R N$, raphe between right coronary and noncoronary sinuses.

additional factors that might have influenced this decision were investigated.

Recursive partitioning using conditional inferences trees ${ }^{15}$ was used to investigate our AA decision process, how the effect of input variables (AA diameter, age, BSA, BAV type) influenced this decision process, and the resulting patterns of AA intervention. Bonferroni-adjusted $P$ values are presented in the decision tree.

Statistical analyses were performed using R, version 3.0.2 (R Development Core Team, 2013; R: A language and environment for statistical computing; R Foundation for Statistical Computing, Vienna, Austria; available at www.R-project.org). The $P$ values from the 2 -sided tests are reported.

\section{RESULTS}

\section{Mortality and Morbidity}

The differences in the hospital mortality and morbidity were not statistically significant between the treatment groups (Table E2). Late survival was also not significantly different statistically for the treatment groups and BAV phenotypes. The life expectancy was comparable to that of to the general German population (Figure E2). The cause of late death is listed in Table E3, and no statistically significant difference between the treatment groups was observed.

\section{Reoperation}

For the purposes of the present study, we have reported reoperations only on the AA. Reoperations on other cardiac structures or for other indications have not been reported. In the no intervention group, 4 reoperations were performed: 1 for type A acute dissection 12 years after the primary operation, with an AA diameter of $43 \mathrm{~mm}$ at the primary operation; 1 for a false aneurysm at the site of aortotomy 1 year postoperatively; 1 for endocarditis of a bioprosthesis concomitant with an aneurysm of the AA of $50 \mathrm{~mm}$ that had developed within 2 years from $43 \mathrm{~mm}$ at the primary operation; 1 for endocarditis of a bioprosthesis and concomitant dilatation of the AA of $45 \mathrm{~mm}$. In the AoP group, 1 reoperation was necessary because of infection of the prosthetic material. In the AAR group, no reoperations occurred.

Freedom from reoperation was not different between the BAV phenotypes or treatment strategies (Figure E2). Freedom from reoperation at 10 years for those with BAV type 0 was $93.9 \%$, BAV type 1 was $95.3 \%$, and BAV type $2 /$ unicuspid was $97.5 \%(P=.7)$. Freedom from reoperation at 10 years for the nontreatment group, AAR group, and AoP group was $94.5 \%, 97.6 \%$, and $96.1 \%$, respectively $(P=.5)$. 


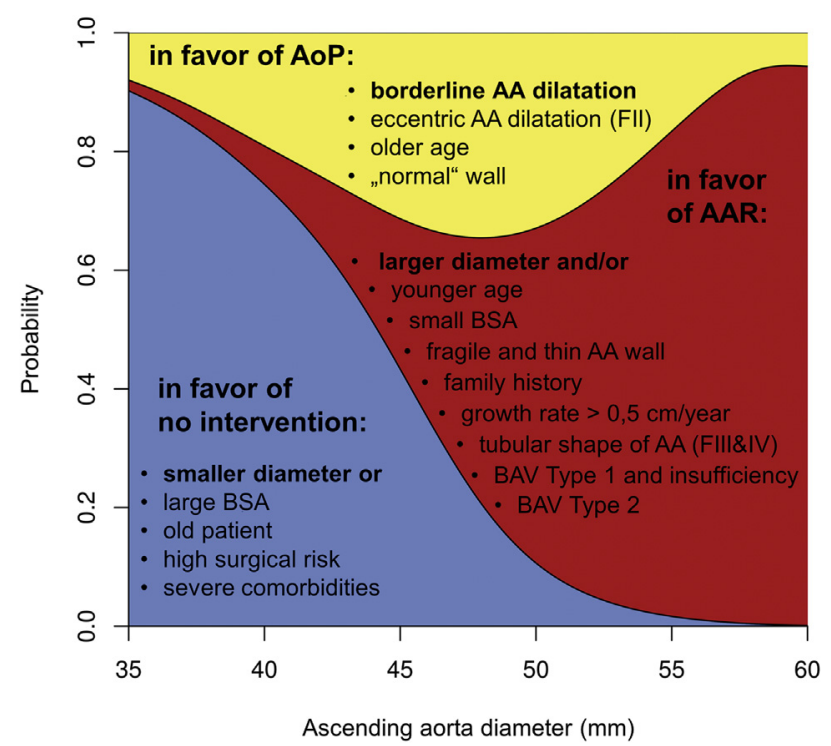

FIGURE 2. The probability (y-axis) that a patient will belong to 1 of the ascending aorta $(A A)$ groups (no intervention, aortoplasty $[A o P]$, AA replacement $[A A R]$ ), given a certain preoperative AA diameter (x-axis). For example, at an AA diameter of $40 \mathrm{~mm}$, the probability for a patient to undergo AA intervention (AoP or AAR) was 0.25 . In contrast, at an AA diameter of $45 \mathrm{~mm}$, the probability of AA intervention increased to 0.57 . Even at smaller diameters, intervention (AAR or AoP) was performed, indicating that not only the diameter was decisive in decision making, but also the other parameters, for a multifactorial individualized approach. $B S A$, Body surface area; $F$, Fazel ${ }^{13} ; B A V$, bicuspid aortic valve.

\section{Management of AA and AA Diameter}

The diameters and demographics stratified by the AA management group are listed in Table E4. Figure 2 (conditional density plot) displays the probability (y-axis) that a patient would belong to 1 of the groups (no intervention, AoP, or AAR), given a certain preoperative AA diameter (x-axis). For example, at an AA diameter of $40 \mathrm{~mm}$, the probability for a patient to receive AA intervention (AoP or AAR) was 0.25 and at a diameter of $43.9 \mathrm{~mm}$ was $50 \%$. The threshold AA diameter for intervention (AoP or AAR) was not fixed but varied from 34 to $51 \mathrm{~mm}$ (mean, 43.9) in relation to the outlined parameters.

\section{Management of AA and BAV Phenotype}

Significantly more AARs were performed in patients with BAV type 2/unicuspid than in those with BAV type 0 and 1 (Table 1). The probability of AAR with respect to a certain diameter was significantly greater for those with BAV type 2/unicuspid (Figure 3). When analyzing the 3 treatment modalities, patients with BAV type 1 LR (raphe between left coronary and right coronary sinuses) and valve insufficiency underwent AAR significantly more often (Table E1). Also, significantly more root interventions (Bentall, David, Yacoub, reconstruction) were performed in those with BAV type $1 \mathrm{LR}$ with an insufficient valve

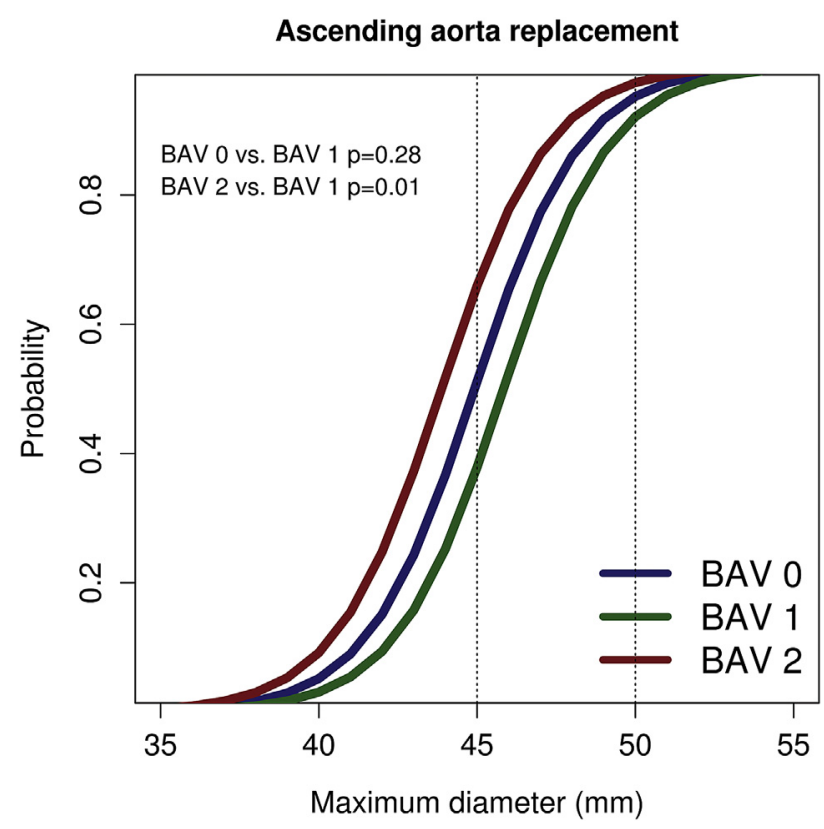

FIGURE 3. Probability of ascending aorta replacement in relation to bicuspid aortic valve $(B A V)$ phenotype. Patients with BAV type 2/unicuspid underwent interventions significantly more often at a certain diameter than did those with BAV type 1 .

lesion than in those with BAV type 1 LR with a combined or stenotic valve lesion ( $36 \%$ vs $11 \%$ vs $5 \%$, respectively; $P<.001)$. A decision tree displaying the variables that exhibited a statistically significant influence in the patient therapy selection process for the population of the present study is shown in Figure 4.

\section{AA and BAV Phenotypes}

In 583 patients ( $54 \%$ of the total) with BAV type 1, data on the AA pattern according to the Fazel classification ${ }^{13}$ were available. For BAV type $1 \mathrm{LR}$ and BAV type $1 \mathrm{RN}$ (raphe between right coronary and noncoronary sinuses), a normal configuration was found in 144 and 29, cluster I in 24 and 5, cluster II in 223 and 28, cluster III in 19 and 8 , and cluster IV in 84 and 19, respectively. Cluster II was more frequent in those with BAV type 1 LR than in those with BAV type $1 \mathrm{RN}(P<.05)$.

\section{DISCUSSION}

The results of the present study have provided some evidence that $\leq 14$ years postoperatively, an individualized multifactorial strategy for treatment of the AA during BAV surgery will lead to excellent results, with low hospital morbidity and mortality, a low rate of reoperation, and survival comparable that of to the general population. The phenotypes BAV type 2/unicuspid and BAV type 1 with insufficiency were found to be new determinants for more aggressive AAR.

Intervention on the AA using AoP or AAR has the aim of preventing later rupture or dissection. This risk is greater in 


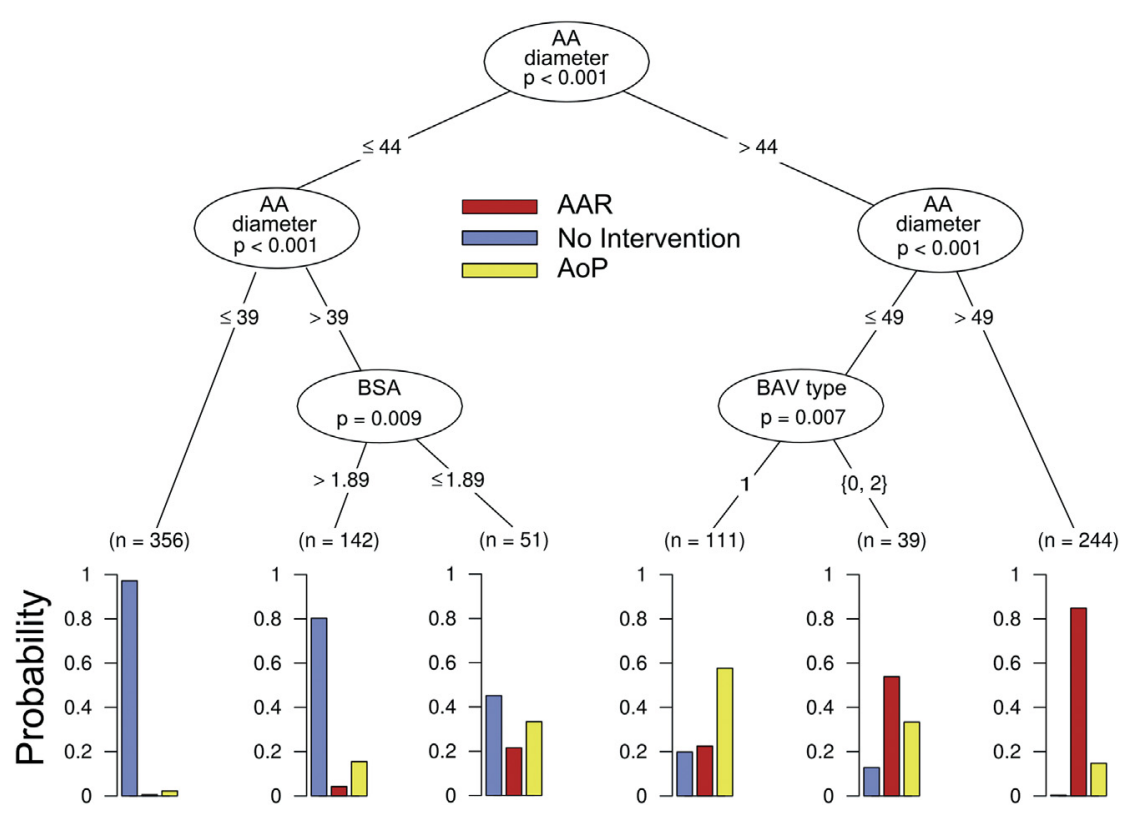

FIGURE 4. Graphic depiction of the decision tree investigating our ascending aorta $(A A)$ management process, the effect of the preoperative variables (AA diameter, body surface area $[B S A]$, bicuspid aortic valve $[B A V]$ type), and the resulting patterns of AA intervention. $A A R$, AA replacement; AoP, aortopathy.

patients with $\mathrm{BAV}^{2-4}$ than in the general population, is present for the whole life expectancy, which can extend to 50 years or even more after the initial operation. The risk also increases owing to aging-related progressive AA dilatation and degeneration. ${ }^{16,17}$ These facts must be considered and weighed against the surgical risk during the decision-making process of when and how to treat the AA and also when interpreting data from follow-up studies, which have rarely exceeded 10 to 15 years of follow-up.

\section{Determining When to Operate on the AA}

Wall tension is the major determinant of the tear-ability or risk of rupture of the AA. According to the law of Laplace, the wall tension includes the AA diameter multiplied by the blood pressure divided by the wall strength.

Physiologically, the AA is outgrown in relation to the BSA after adolescence. However, it still increases in diameter with age ${ }^{16}$ and in association with AA tissue degeneration, ${ }^{17}$ both enhancing the risk of rupture or dissection. This risk is considerable at a diameter of $\geq 5.5 \mathrm{~cm}^{18}$ The current guidelines ${ }^{\mathrm{E} 1}$ have recommend surgery on the $\mathrm{AA}$ in patients with a diameter of $>4.5 \mathrm{~cm}$ without age- and BSA-related differentiation. However, the question remain regarding how we should treat a young patient with a borderline diameter of the AA at valve surgery, a diameter that with aging-related dilatation and degeneration during the patient's long life expectancy will increase to the cutoff value or more within some years after surgery, keeping in mind the increased risk of rupture in patients with $\mathrm{BAV}^{2-4}$ Considering these facts, we believe that in addition to the
AA diameter, at the least, the patient's age and BSA should be included in the decision-making process for every patient.

Hypertension, the second factor, should be thoroughly kept in mind and treated aggressively, although increases in blood pressure owing to emotional stress and different situations have been difficult to capture. Furthermore, medical therapy for blood pressure control and limitation of AA dilation can play a crucial role in the fate of the AA and should be considered in future studies.

The third factor is wall strength. When the AA is transected for valve replacement, visual examination by an experienced surgeon can provide some impression of the strength of the AA wall, defined as fragility or thinning of the tissue, which was recently published for surgery of type A dissection. ${ }^{19}$ However, the subjectivity of this qualitative criterion is great and requires additional objectivization. Whether the different shapes of the AA according to Fazel and colleagues ${ }^{13}$ will correlate with the perceived tissue quality remains to be evaluated. Furthermore, genetics and hemodynamics could be potential factors causing tissue weakness. Some evidence has shown that the genetic defects causing the BAV pathologic features could also have an effect on the tissue of the AA. ${ }^{7}$ Hemodynamic shear stress has also been reported to accelerate AA dilatation. ${ }^{9}$ Both hemodynamic and genetic reasons could be related to the BAV phenotype. Thus, we found that patients with BAV type 2/unicuspid underwent AAR significantly more often, independent of the AA diameter (Figure 3). Thus, roughly $50 \%$ of patients with BAV type 2/unicuspid had undergone AAR at a 
diameter of $43.9 \mathrm{~mm}$. When the BAV phenotypes were stratified according to the preoperative hemodynamics, patients with BAV type 1 LR with valve insufficiency had undergone AAR more often than no intervention (Table E1). This fits with the findings from Roberts and colleagues, ${ }^{20}$ who reported that patients with regurgitant $\mathrm{BAV}$ s had more pronounced pathologic features of the AA wall. This was supported by the finding that significantly more root interventions were performed in the BAV type 1 LR group with an insufficient valve than in the BAV type 1 LR group with combined or stenotic valve lesions. In a recent study, Thanassoulis and colleagues ${ }^{\mathrm{E} 4}$ showed that those with BAV type 1 LR and moderate to severe regurgitation were more likely to have a dilated aorta, confirming our results. Whether these BAV types reflect a more severe form of genetic abnormality and a more malignant form of aortopathy is unknown. Nevertheless, the present study has provided some evidence that BAV type 2/unicuspid and BAV type 1 with valve insufficiency could be determinants for more aggressive AAR in our practice. Furthermore, patients who underwent root surgery had a significantly larger AA diameter than those who id not undergo root surgery (54 vs $49 \mathrm{~mm}$, $P<.001$ ), possibly indicating a more severe form of aortopathy in these patients.

Significantly more patients with BAV type 1 LR had a cluster II pattern with regional AA dilatation along the convexity than did those with BAV type $1 \mathrm{RN}$, indicating that the valve phenotypes might be associated with different AA configurations, probably related in part to different flow and shear stress characteristics. ${ }^{\text {E2 }}$ These findings were also reflected by the differences in the matrix metalloproteinases and endogenous tissue inhibitors. ${ }^{\mathrm{E}}$

Taking together, the results of the present study have shown that more factors might be influencing the decision making than just the diameter (Figure 2). Figure 4 shows the relatively simple decision tree from our data that only included the AA diameter, BSA, and BAV type. Other determinants, such as family history, growth progression, and tissue strength, were not included, because they occurred too seldom or were qualitative.

\section{Operating on AA Dilatation-AAR or AoP?}

Although AAR seems theoretically to be the safest solution to treat AA dilatation, it has its own risks-first, increased operative mortality and morbidity owing to the longer operative time. In our study, the hospital mortality, including after valve surgery, was not increased in the AAR group, although AAR was accompanied by the greatest rate of hemiarch surgery with circulatory arrest, indicating that this surgical risk might be negligible in experienced centers. Second, the nonelasticity of the Dacron tube graft causes a loss of the Windkessel function, with the potential for aortic root aneurysm, left ventricular hypertrophy, late cardiac mortality, increased wall tension of the remaining aorta and, thus, potentially, type B dissection, annulus dilatation, valve dysfunction, and exercise impairment. ${ }^{21-24}$ In our study, we did not detect these adverse events; however, the follow-up period was too short for a final judgment, and we did not investigate all of these items. Because of these potential shortcomings, we used AAR mainly in patients with larger AA diameters (Table E4).

In contrast to AAR, AoP preserves the Windkessel function. ${ }^{25}$ The results of AoP have been reported to be satisfactory, safe, and durable if the diameter can be adequately reduced to about $3.6 \mathrm{~cm} .{ }^{26}$ It should be performed in patients with borderline dilatation ${ }^{27}$ (Table E4, Figure 2) and not in patients with an insufficient valve ${ }^{28}$; AoP can also be performed in those with post-stenotic AA dilatation and in elderly patients. ${ }^{29}$ We followed this policy and performed AoP at the convexity of the AA, the portion probably most affected by histologic abnormalities. ${ }^{30}$ To date, the results from our study have supported this strategy; only 1 reoperation was necessary in the AoP group owing to infection of the prosthetic material. Nevertheless, a potential risk exists for later dilation and reoperation, leaving the application of AoP controversial and largely determined by surgeon preference until we have more reliable long-term data.

Our individualized policy for treatment of the AA during BAV surgery led to a more aggressive approach, with $33.5 \%$ of patients undergoing an intervention, compared with a recently published incidence of $20 \% .{ }^{31}$ Our results reflect the observed trend of an increased incidence of thoracic aorta surgery in patients with BAV. ${ }^{32}$ We believe the known increased risk of AA complications in patients with $\mathrm{BAV},{ }^{2-4}$ the age-related increase in AA diameter with tissue degeneration, and that smaller size AAs can rupture $(40 \%$ of acute type A dissections occurred at AA diameters of $<50 \mathrm{~mm}$ in the International Registry of Acute Aortic Dissection trial ${ }^{33}$ ) justify and support an individualized multifactorial, more aggressive AA approach, especially for those with BAV type 2/unicuspid and BAV type 1 with regurgitation during valve surgery. Four reoperations on the AA were performed in the no intervention group during the follow-up period. Whether this finding is a hint to be even more aggressive remains to be seen after longer follow-up periods. Our policy has been supported by the report from Russo and colleagues, ${ }^{34}$ advocating a more prophylactic replacement approach, and, most recently, by the report from Stanger and colleagues, ${ }^{19}$ emphasizing a potentially lower threshold for prophylactic replacement of the AA in experienced centers, particularly in patients with aortic regurgitation, hypertension, and thinning of the aortic wall.

\section{The Future}

The development of prostheses with durable flexibility that preserve the Windkessel function over time could 
reduce a number of the potential side effects of the commonly used unelastic Dacron prostheses and thus might lower the threshold for AAR. The development of a histologic quick test could also be helpful in decision making.

Our study reports on a cautious beginning of an individualized differentiated strategy. For more sophisticated risk calculation ${ }^{2}$ and, thus, a meaningful individualized decision tree weighing the risks and benefits, we need additional, ideally lifelong, information on these factors, genes, biomarkers, other genetically related parameters, and environmental data (eg, hypertension, sheer stress, turbulence) to determine the fate of the AA. We also require follow-up data on procedure-related outcomes. We agree with the views of Fedak and Verma ${ }^{\mathrm{E} 5}$ that "the current guidelines for aortic resection and patients with aortopathy are too simple" and "personally tailored approaches for the patients with bicuspid aortic syndrome are crucial because the disease is clinically heterogeneous, making individual predictions particularly challenging." This goal, however, requires acquisition of a large amount of data. ${ }^{2}$ An encouraging proposal for more effective data collection on a larger, or even global, scale was recently reported by Moody. ${ }^{35}$

\section{Study Limitations and Strengths}

Measurement of the AA diameter was performed using several techniques, just as is usually the case in clinical practice. Thus, differences in these measurement methods could have led to measurement-related differences in the AA diameter. The differences in the measurement methods were also a reason to not rely on the diameter alone, but to include other parameters for the decision regarding AA treatment. Furthermore, we would have preferred to obtain $>59 \%$ of AA diameter measurements in the no intervention group; however, for many of these patients, AA diameters that seemed normal were not measured but only described as "normal."

The mean follow-up period was relatively short at 5.4 years, and only $14 \%$ of patients $(n=189)$ were followed up for $>10$ years. Thus, the implications are limited, and longer follow-up periods are necessary to consolidate our management policy.

The development of the AA diameter postoperatively, especially in the no intervention and AoP groups, would be of great interest, because it is possible that some AAs might have become dilated. This would indicate the potential for a change in the protocol in favor of more frequent AAR. This will be evaluated in future research. In a recent publication, ${ }^{8}$ we could not find a progressive increase in the AA diameter after correction of pathologic hemodynamics using a Ross procedure compared with normal individuals. Also, we could not demonstrate whether any type of intervention or no intervention was the best treatment modality, we could only present our results and our protocol. To consolidate our results, more information will be necessary. One advantage of the present study was its design concerning the integration of individual parameters for decision making as an encouraging, and theoretically reasonable, concept. Another advantage was the relatively large number of BAV phenotypes.

We would like to thank Michael Diwoky and Tobias Frin for their excellent data management and analyses and their assistance in preparing our report for publication.

\section{References}

1. Ward C. Clinical significance of the bicuspid aortic valve. Heart. 2000;83:81-5.

2. Sievers HH, Sievers HL. Aortopathy in bicuspid aortic valve disease-genes or hemodynamics? Or Scylla and Charybdis? Eur J Cardiothorac Surg. 2011;39: 803-4.

3. Fedak PW, Verma S, David TE, Leask RL, Weisel RD, Butany J. Clinical and pathophysiological implications of a bicuspid aortic valve. Circulation. 2002; 106:900-4.

4. Michelena HI, Khanna AD, Mahoney D, Margaryan E, Topilsky Y, Suri RM, et al. Incidence of aortic complications in patients with bicuspid aortic valves. JAMA. 2011:306:1104-12.

5. Verma S, Yanagawa B, Kalra S, Ruel M, Peterson MD, Yamashita MH, et al. Knowledge, attitudes, and practice patterns in surgical management of bicuspid aortopathy: a survey of 100 cardiac surgeons. J Thorac Cardiovasc Surg. 2013; 146:1033-40.e4.

6. Lee SH, Kim JB, Kim DH, Jung SH, Choo SJ, Chung CH, et al. Management of dilated ascending aorta during aortic valve replacement: valve replacement alone versus aorta wrapping versus aorta replacement. J Thorac Cardiovasc Surg. 2013;146:802-9.

7. Kent KC, Crenshaw ML, Goh DL, Dietz HC. Genotype-phenotype correlation in patients with bicuspid aortic valve and aneurysm. J Thorac Cardiovasc Surg. 2013;146:158-65.e1.

8. Charitos EI, Stierle U, Petersen M, Mohamed SA, Hanke T, Schmidtke C, et al. The fate of the bicuspid aortic valve aortopathy after aortic valve replacement. Eur J Cardiothorac Surg. 2014;45:e128-35.

9. Kim YG, Sun BJ, Park GM, Han S, Kim DH, Song JM, et al. Aortopathy and bicuspid aortic valve: haemodynamic burden is main contributor to aortic dilatation. Heart. 2012;98:1822-7.

10. Sievers HH, Schmidtke C. A classification system for the bicuspid aortic valve from 304 surgical specimens. J Thorac Cardiovasc Surg. 2007;133: 1226-33.

11. Mookadam F, Thota VR, Garcia-Lopez AM, Emani UR, Alharthi MS Zamorano J, et al. Unicuspid aortic valve in adults: a systematic review. J Hear Valve Dis. 2010;19:79-85.

12. Sievers HH. Reflections on reduction ascending aortoplasty's liveliness. J Thorac Cardiovasc Surg. 2004;128:499-501.

13. Fazel SS, Mallidi HR, Lee RS, Sheehan MP, Liang D, Fleischman D, et al. The aortopathy of bicuspid aortic valve disease has distinctive patterns and usually involves the transverse aortic arch. J Thorac Cardiovasc Surg. 2008;135:901-7.

14. Pohar M, Stare J. Relative survival analysis in R. Comput Methods Programs Biomed. 2006;81:272-8.

15. Hothorn T, Hornik K, Zeileis A. Unbiased recursive partitioning: a conditional inference framework. J Comput Graph Stat. 2006;15:651-74.

16. Roman MJ, Devereux RB, Kramer-Fox R, O’Loughlin J. Two-dimensional echocardiographic aortic root dimensions in normal children and adults. Am J Cardiol. 1989;64:507-12.

17. Schlatmann TJ, Becker AE. Histologic changes in the normal aging aorta: implications for dissecting aortic aneurysm. Am J Cardiol. 1977;39:13-20.

18. Elefteriades JA. Natural history of thoracic aortic aneurysms: indications for surgery, and surgical versus nonsurgical risks. Ann Thorac Surg. 2002;74 S1877-80.

19. Stanger O, Schachner T, Gahl B, Oberwalder P, Englberger L, Thalmann M, et al Type A aortic dissection after nonaortic cardiac surgery. Circulation. 2013;128: 1602-11.

20. Roberts WC, Vowels TJ, Ko JM, Filardo G, Hebeler RF Jr, Henry AC, et al Comparison of the structure of the aortic valve and ascending aorta in adults having aortic valve replacement for aortic stenosis versus for pure aortic 
regurgitation and resection of the ascending aorta for aneurysm. Circulation. 2011;123:896-903.

21. Simon-Kupilik N, Schima H, Huber L, Moidl R, Wipplinger G, Losert U, et al. Prosthetic replacement of the aorta is a risk factor for aortic root aneurysm development. Ann Thorac Surg. 2002;73:455-9.

22. Safar ME, Toto-Moukouo JJ, Bouthier JA, Asmar RE, Levenson JA, Simon AC, et al. Arterial dynamics, cardiac hypertrophy, and antihypertensive treatment. Circulation. 1987;75:I156-61.

23. Scharfschwerdt M, Sievers HH, Greggersen J, Hanke T, Misfeld M. Prosthetic replacement of the ascending aorta increases wall tension in the residual aorta. Ann Thorac Surg. 2007;83:954-7.

24. Kim SY, Hinkamp TJ, Jacobs WR, Lichtenberg RC, Posniak H, Pifarré R. Effect of an inelastic aortic synthetic vascular graft on exercise hemodynamics. Ann Thorac Surg. 1995;59:981-9.

25. Walker T, Bail DH, Gruler M, Vonthein R, Steger V, Ziemer G. Unsupported reduction ascending aortoplasty: fate of diameter and of Windkessel function. Ann Thorac Surg. 2007;83:1047-53.

26. Bauer M, Pasic M, Schaffarzyk R, Siniawski H, Knollmann F, Meyer R, et al. Reduction aortoplasty for dilatation of the ascending aorta in patients with bicuspid aortic valve. Ann Thorac Surg. 2002;73:720-3.

27. Niclauss L, Delay D, Ruchat P, von Segesser LK. Reduction aortoplasty: safe and durable treatment for borderline dilatation in selected patients. J Heart Valve Dis. 2012;21:584-90.
28. Mueller XM, Tevaearai HT, Genton CY, Hurni M, Ruchat P, Fischer AP, et al Drawback of aortoplasty for aneurysm of the ascending aorta associated with aortic valve disease. Ann Thorac Surg. 1997;63:762-6.

29. Gill M, Dunning J. Is reduction aortoplasty (with or without external wrap) an acceptable alternative to replacement of the dilated ascending aorta? Interact Cardiovasc Thorac Surg. 2009;9:693-7.

30. Mohamed SA, Misfeld M, Hanke T, Charitos EI, Bullerdiek J, Belge G, et al. Inhibition of caspase-3 differentially affects vascular smooth muscle cell apoptosis in the concave versus convex aortic sites in ascending aneurysms with a bicuspid aortic valve. Ann Anat. 2010;192:145-50.

31. Svensson LG, Blackstone EH, Cosgrove DM 3rd. Surgical options in young adults with aortic valve disease. Curr Probl Cardiol. 2003;28:417-80.

32. Opotowsky AR, Perlstein T, Landzberg MJ, Colan SD, O'Gara PT, Body SC, et al. A shifting approach to management of the thoracic aorta in bicuspid aortic valve. J Thorac Cardiovasc Surg. 2013;146:339-46.

33. Pape LA, Tsai TT, Isselbacher EM, Oh JK, O'Gara PT, Evangelista A, et al Aortic diameter $>$ or $=5.5 \mathrm{~cm}$ is not a good predictor of type A aortic dissection: observations from the International Registry of Acute Aortic Dissection (IRAD) Circulation. 2007;116:1120-7.

34. Russo CF, Mazzetti S, Garatti A, Ribera E, Milazzo A, Bruschi G, et al. Aortic complications after bicuspid aortic valve replacement: long-term results. Ann Thorac Surg. 2002;74:S1773-6.

35. Moody A. Perspective: the big picture. Nature. 2013;502:S95.

\title{
EDITORIAL COMMENTARY
}

\section{Bicuspid aortopathy and the development of individualized resection strategies}

\author{
Paul W. M. Fedak, MD, PhD, FRCSC, ${ }^{\text {a,b }}$ and Subodh Verma, MD, PhD, FRCSC ${ }^{\mathrm{c}, \mathrm{d}}$
}

See related article on pages 2072-80.

In an effort to better understand current surgical approaches, we compared the knowledge and attitudes of individual surgeons toward the diagnosis and management of bicuspid aortopathy. ${ }^{1}$ Surprisingly, surgeons' approaches often went outside established guidelines, with marked differences in

From the Bicuspid Aortic Valve Program, ${ }^{\mathrm{a}}$ Bluhm Cardiovascular Institute, Northwestern Memorial Hospital, Northwestern University, Chicago, Ill; Libin Cardiovascular Institute of Alberta, ${ }^{\mathrm{b}}$ University of Calgary, Calgary, Alberta, Canada; Division of Cardiac Surgery, ${ }^{\mathrm{c}} \mathrm{Li} \mathrm{Ka}$ Shing Knowledge Institute of St Michael's Hospital, Toronto, Ontario, Canada; and Department of Surgery, ${ }^{\mathrm{d}}$ University of Toronto, Ontario, Canada.

Disclosures: Authors have nothing to disclose with regard to commercial support. Received for publication Sept 18, 2014; accepted for publication Sept 18, 2014

Address for reprints: Subodh Verma, MD, PhD, FRCSC, Division of Cardiac Surgery, St Michael's Hospital, Suite 8-003, Bond Wing, 30 Bond St, Toronto, Ontario M5B 1W8, Canada (E-mail: vermasu@smh.ca).

J Thorac Cardiovasc Surg 2014;148:2080-1 $0022-5223 / \$ 36.00$

Copyright (c) 2014 Published by Elsevier Inc. on behalf of The American Association for Thoracic Surgery

http://dx.doi.org/10.1016/j.jtcvs.2014.09.059 the timing, extent, and type of operative strategy of aortic resection. Bicuspid aortopathy is a commonly encountered clinical scenario, so why are surgeons so disparate and noncompliant with current recommendations? We believe that the heterogeneous nature of the disease and its diverse clinical phenotypes ${ }^{2}$ may influence a surgeon's threshold for aortic replacement, despite current guidelines. Unfortunately, there are no consensus recommendations on the type or extent of aortic repair for an individual patient with bicuspid aortopathy, and no randomized clinical trials are available to better inform clinicians as to whether an aggressive versus conservative approach is appropriate. Although arm-deep in a patient's chest and inspired by the best intentions, surgeons might avoid the recommendations in selected patients and recognize that contemporary guidelines for aortic resection in patients with bicuspid aortic valve based solely on maximal aortic diameter are deficient and lack an appreciation for the numerous factors that may underlie disease progression.

To achieve optimal clinical outcomes for bicuspid aortopathy, individualized surgical approaches for patients with bicuspid aortic valve disease may be a necessity. In their report in this issue of the Journal, Sievers and 


\section{E-References}

E1. Bonow RO, Carabello BA, Kanu C, de Leon AC Jr, Faxon DP, Freed MD, et al. ACC/AHA 2006 guidelines for the management of patients with valvular heart disease: a report of the American College of Cardiology/American Heart Association Task Force on Practice Guidelines (writing committee to revise the 1998 Guidelines for the Management of Patients With Valvular Heart Disease): developed in collaboration with the Society of Cardiovascular Anesthesiologists: endorsed by the Society for Cardiovascular Angiography and Interventions and the Society of Thoracic Surgeons. Circulation. 2006;114:e84-231.

E2. Mahadevia R, Barker AJ, Schnell S, Entezari P, Kansal P, Fedak PW, et al. Bicuspid aortic cusp fusion morphology alters aortic three-dimensional outflow patterns, wall shear stress, and expression of aortopathy. Circulation. 2014;129: $673-82$.

E3. Ikonomidis JS, Ruddy JM, Benton SM Jr, Arroyo J, Brinsa TA, Stroud RE, et al. Aortic dilatation with bicuspid aortic valves: cusp fusion correlates to matrix metalloproteinases and inhibitors. Ann Thorac Surg. 2012;93:457-63.

E4. Thanassoulis G, Yip JW, Filion K, Jamorski M, Webb G, Siu SC, et al. Retrospective study to identify predictors of the presence and rapid progression of aortic dilatation in patients with bicuspid aortic valves. Nat Clin Pract Cardiovasc Med. 2008;5:821-8.

E5. Fedak PW, Verma S. The molecular fingerprint of bicuspid aortopathy. J Thorac Cardiovasc Surg. 2013;145:1334.

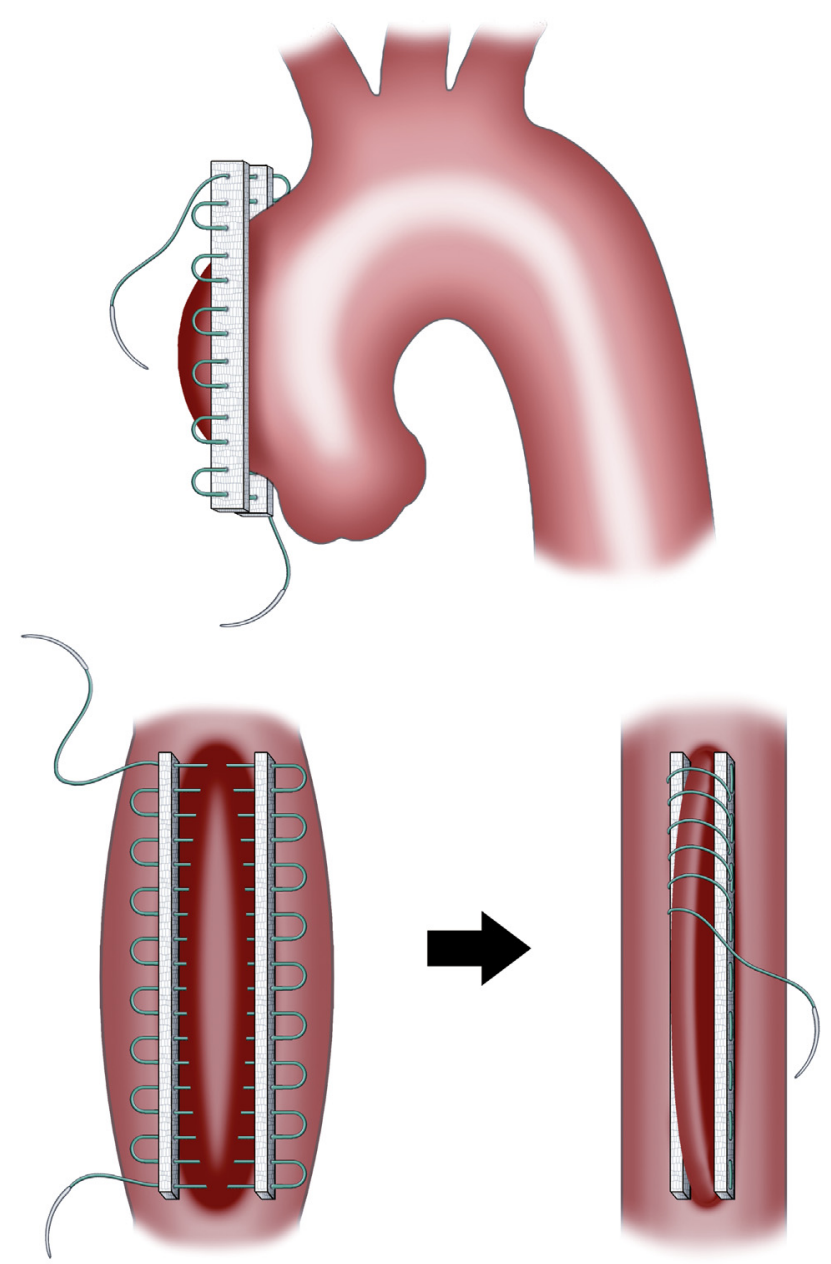

FIGURE E1. Schematic presentation of the surgical technique for aortopathy. The eccentric part of the ascending aorta is plicated between 2 Teflon felts using a mattress and over and over continuous suture. 

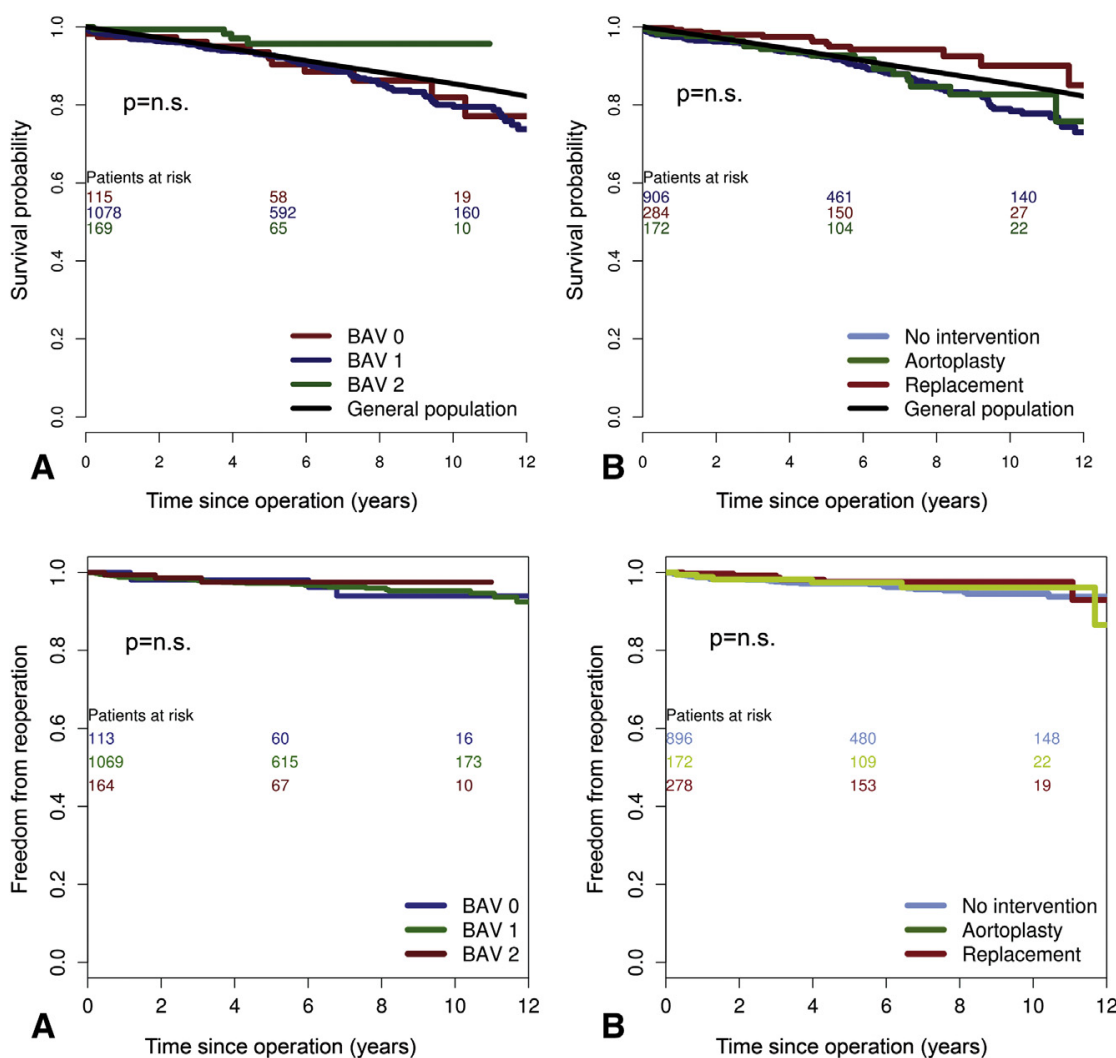

FIGURE E2. Survival (upper graphs) and freedom from reoperation (lower graphs) in relation to (A) bicuspid aortic valve (BAV) phenotypes and (B) management of ascending aorta. n.s., Not significant. 
TABLE E1. BAV phenotypes and hemodynamics stratified by AA management

\begin{tabular}{|c|c|c|c|c|c|}
\hline BAV type & Total & $\begin{array}{c}\text { No } \\
\text { intervention }\end{array}$ & AoP & AAR & $\begin{array}{c}P \\
\text { value }\end{array}$ \\
\hline Type 0 , ap & $48(100)$ & 37 (100) & $2(100)$ & $9(100)$ & $\mathrm{NC}$ \\
\hline Insufficiency & $12(25)$ & $11(29.7)$ & $0(0)$ & $1(11.1)$ & \\
\hline Stenosis & $24(50)$ & $19(51.4)$ & $0(0)$ & $5(55.6)$ & \\
\hline Combined & $12(25)$ & $7(18.9)$ & $2(100)$ & $3(33.3)$ & \\
\hline Type 0, lat & $58(100)$ & 34 (100) & $9(100)$ & $15(100)$ & $\mathrm{NC}$ \\
\hline Insufficiency & $12(20.7)$ & $6(17.6)$ & $1(11.1)$ & $5(33.3)$ & \\
\hline Stenosis & 33 (56.9) & $23(67.6)$ & $6(66.7)$ & $4(26.7)$ & \\
\hline Combined & $13(22.4)$ & $5(14.7)$ & $2(22.2)$ & $6(40)$ & \\
\hline Type 1 , LR & $888(100)$ & $603(100)$ & 118 (100) & $167(100)$ & \\
\hline Insufficiency & $202(22.7)$ & 117 (19.4) & 27 (22.9) & $58(34.7)$ & $*, \dagger$ \\
\hline Stenosis & $390(43.9)$ & $291(48.3)$ & 48 (40.7) & $51(30.5)$ & * \\
\hline Combined & $296(33.3)$ & $195(32.3)$ & $43(36.4)$ & $58(34.7)$ & NS \\
\hline Type 1 , NL & $22(100)$ & $19(100)$ & $2(100)$ & $1(100)$ & $\mathrm{NC}$ \\
\hline Insufficiency & $6(27.3)$ & $5(26.3)$ & $0(0)$ & $1(100)$ & \\
\hline Stenosis & $11(50)$ & $10(52.6)$ & $1(50)$ & $0(0)$ & \\
\hline Combined & $5(22.7)$ & $4(21.1)$ & $1(50)$ & $0(0)$ & \\
\hline Type 1 , RN & $166(100)$ & $119(100)$ & $19(100)$ & $28(100)$ & $\mathrm{NC}$ \\
\hline Insufficiency & $32(19.3)$ & $22(18.5)$ & $3(15.8)$ & $7(25)$ & \\
\hline Stenosis & $79(47.6)$ & $66(55.5)$ & $8(42.1)$ & $5(17.9)$ & \\
\hline Combined & $55(33.1)$ & $31(26.1)$ & $8(42.1)$ & $16(57.1)$ & \\
\hline $\begin{array}{c}\text { Type 2, LR/RN/ } \\
\text { unicuspid }\end{array}$ & $153(100)$ & 77 (100) & $17(100)$ & $59(100)$ & $\mathrm{NC}$ \\
\hline Insufficiency & $4(2.6)$ & $1(1.3)$ & $0(0)$ & $3(5.1)$ & \\
\hline Stenosis & $62(40.5)$ & $37(48.1)$ & $5(29.4)$ & $20(33.9)$ & \\
\hline Combined & $87(56.9)$ & $39(50.6)$ & $12(70.6)$ & $36(61)$ & \\
\hline
\end{tabular}

Data presented as $\mathrm{n}(\%) . B A V$, Bicuspid aortic valve; $A A$, ascending aorta; $A o P$, aortopathy; $A A R$, AA replacement; $a p$, anteroposterior; $N C$, not calculated (number of patients too small); lat, lateral; $L R$, raphe between left coronary and right coronary sinuses; $N S$, not significant; $N L$, raphe between noncoronary and left coronary sinuses; $R N$, raphe between right coronary and noncoronary sinuses. *No intervention versus AAR, $P<.001$. $\dagger$ AAR versus AoP, $P<.05$.

TABLE E2. Postoperative outcomes $(\leq \mathbf{3 0}$ d) stratified by AA management

\begin{tabular}{lcccc}
\hline \multicolumn{1}{c}{ Outcome } & $\begin{array}{c}\text { Total } \\
(\mathbf{n}=\mathbf{1 3 6 2})\end{array}$ & $\begin{array}{c}\text { No intervention } \\
(\mathbf{n = 9 0 6})\end{array}$ & $\begin{array}{c}\text { AoP } \\
(\mathbf{n = 1 7 2})\end{array}$ & $\begin{array}{c}\text { AAR } \\
(\mathbf{n}=\mathbf{2 8 4})\end{array}$ \\
\hline Hospital mortality & $12(0.9)$ & $10(1.1)$ & $1(0.6)$ & $1(0.4)$ \\
IABP & $22(1.6)$ & $18(2.0)$ & $1(0.6)$ & $3(1.1)$ \\
$\begin{array}{l}\text { Reoperation for } \\
\text { bleeding }\end{array}$ & $66(4.8)$ & $39(4.3)$ & $7(4.1)$ & $20(7.0)$ \\
$\begin{array}{l}\text { Permanent } \\
\text { stroke }>72 \mathrm{~h}\end{array}$ & $5(0.4)$ & $4(0.4)$ & $1(0.6)$ & $0(0)$ \\
$\begin{array}{l}\text { Dialysis } \\
\text { D }\end{array}$ & $40(2.9)$ & $32(3.5)$ & $5(2.9)$ & $3(1.1)$ \\
\hline
\end{tabular}

Data presented as $\mathrm{n}(\%) . A A$, Ascending aorta; $A o P$, aortopathy; $A A R$, AA replacement; $I A B P$, intra-aortic balloon pump.
TABLE E3. Cause of late death ( $>30$ d) stratified by AA management

\begin{tabular}{lcccc}
\hline \multicolumn{1}{c}{ Variable } & $\begin{array}{c}\text { Total } \\
(\mathbf{n}=\mathbf{1 3 6 2})\end{array}$ & $\begin{array}{c}\text { No intervention } \\
(\mathbf{n = 9 0 6})\end{array}$ & $\begin{array}{c}\text { AoP } \\
(\mathbf{n}=\mathbf{1 7 2})\end{array}$ & $\begin{array}{c}\text { AAR } \\
(\mathbf{n}=\mathbf{2 8 4})\end{array}$ \\
\hline Cause of late death & & & & \\
Cardiac & $29(2.1)$ & $24(2.6)$ & $3(1.7)$ & $2(0.7)$ \\
Noncardiac & $72(5.3)$ & $52(5.7)$ & $11(6.4)$ & $9(3.2)$ \\
Unknown & $17(1.2)$ & $12(1.3)$ & $4(2.3)$ & $1(0.4)$ \\
LOR $(\% / p t-y)$ & 0.40 & 0.49 & 0.30 & 0.14 \\
\hline
\end{tabular}

Data presented as n (\%). AA, Ascending aorta; $A o P$, aortopathy; $A A R$, AA replacement; $L O R$, linearized occurrence rate; $p t-y$, patient-year.
TABLE E4. AA diameter, age, BSA, and gender stratified by AA management

\begin{tabular}{|c|c|c|c|c|}
\hline Variable & No intervention & AoP & AAR & $\begin{array}{c}P \\
\text { value }\end{array}$ \\
\hline Total & 906 (100) & $172(100)$ & $284(100)$ & \\
\hline $\begin{array}{l}\text { Patients with } \\
\text { measured diameter }\end{array}$ & $535(59.1)$ & $162(94.2)$ & 277 (97.5) & \\
\hline Diameter (mm) & & & & $*, \dagger, \ddagger$ \\
\hline Mean \pm SD & $36.7 \pm 5.1$ & $46.5 \pm 4.9$ & $53.1 \pm 7.3$ & \\
\hline Median & 37 & 46 & 52 & \\
\hline Range & $22-51$ & $35-65$ & $34-84$ & \\
\hline Age (y) & $54.1 \pm 15.0$ & $57.3 \pm 14.3$ & $52.5 \pm 12.9$ & $\ddagger, \S$ \\
\hline $\operatorname{BSA}\left(\mathrm{m}^{2}\right)$ & $1.98 \pm 0.20$ & $1.98 \pm 0.21$ & $2.01 \pm 0.22$ & || \\
\hline Male gender & 425 (79.4) & $118(72.8)$ & $219(79.1)$ & NS \\
\hline
\end{tabular}

